\title{
Inhibition Efficiency of Copper Corrosion in a Neutral Chloride Solution by Barbituric and Thiobarbituric Acids
}

\author{
Howida S. Mandour, ${ }^{1, *}$ Amal M. Abdel-Karim ${ }^{1}$ and Ahlam M. Fathi ${ }^{1}$ \\ ${ }^{1}$ National Research Centre, Physical Chemistry Department, 33 El Bohouth St. \\ (former El Tahrir St.), P.O. 12622, Dokki, Giza, Egypt \\ *Corresponding author: hmandour77@gmail.com
}

Received 18/03/2018; accepted 20/06/2018

https://doi.org/10.4152/pea.202102085

\begin{abstract}
Environmental green compounds have emerged as powerful inhibitors for metals and alloys corrosion. So, this article attempts to show that barbituric (BA) and thiobarbituric acids (TBA) are good green corrosion inhibitors for copper immersed in $0.6 \mathrm{~mol} / \mathrm{L}$ $\mathrm{NaCl}$. A combination of quantitative and qualitative tools were used in this investigation, such as electrochemical impedance spectroscopy (EIS), potentiodynamic polarization, FT-IR spectroscopy, scanning electron microscopy (SEM) and energy dispersive X-ray spectroscopy (EDX). Polarization measurements indicate that these compounds can function as mixed type inhibitors. It was found that the adsorption of these inhibitors onto the copper surface obeyed Flory-Huggins isotherm. Also, the effect of temperature in the inhibitors absence and presence was studied according to Arrhenius isotherm. Some thermodynamic functions of dissolution and adsorption processes were calculated, such as activation energy $\left(E_{a}\right)$, enthalpy $\left(\Delta H^{*}\right)$, free energy $\left(\Delta G^{0}\right)$ and entropy $\left(\Delta S^{*}\right)$. The barbituric and thiobarbituric acids recorded high inhibition efficiency of copper corrosion at concentrations of $5 \times 10^{-3} \mathrm{~mol} / \mathrm{L}$ and $1 \times 10^{-3}$ $\mathrm{mol} / \mathrm{L}$, respectively.
\end{abstract}

Keywords: barbituric, thiobarbituric, potentiodynamic polarization and Flory-Huggins isotherm.

\section{Introduction}

Corrosion is a continuous and complicated problem with metal deterioration resulting from chemical attack or from a reaction with the environment ${ }^{1,2}$. Actually, corrosion cannot be completely eliminated, but can be retarded or prevented to some extent by using inhibitors. Recently, the world gave more attention to the environment protection, and the use of non-toxic green inhibitors is the main concern of many researchers ${ }^{3-6}$.

The significant effect of corrosion inhibitors depends on the complexation with metal, and on the extent of their dissolution in water. However, the formation of a stable and insoluble complex between inhibitor molecules and hydrated metal ions leads up to a decrease in metal dissolution, thus having an effect of 
corrosion retarding. Clearly, corrosion inhibition efficiency is controlled by the existence of heteroatoms (e.g. O, N and S) with high electron density ${ }^{7-9}$, aromatic rings with polar groups and $\pi$-electrons in the inhibitor molecules ${ }^{6,10,11}$. The electron pairs of mercapto ${ }^{12}$ and amino group ${ }^{13}$ can support the inhibitor molecules adsorption onto the metal surface. Naturally, these compounds can be adjusted to progress the strength of their adsorption bonds to the conversed metals. Also, this can be done by retarding the cathodic and/or anodic processes, or promoting adsorption onto the metallic surface by forming an adsorbed layer which acts as a compact barrier film ${ }^{14}$.

Pharmaceutically active substances, such as barbituric acid and its derivative, thiobarbituric acid, are used as corrosion inhibitors for mild steel protection in different media ${ }^{14-17}$. TBA adsorption onto the mild steel surface took place mainly through electrostatic interaction ${ }^{3}$. Udhayakala et al. ${ }^{17}$ used Fukui function (which provides information on the atoms in a molecule which have a higher tendency to either loose or accept an electron or pair of electrons) to show the nucleophilic and electrophilic attacking sites in the inhibitors.

Copper is suitable for a wide range of applications in submarine engineering ${ }^{18}$, seawater desalination, pipelines and heat exchangers ${ }^{19}$. So, copper corrosion inhibition is a continuing concern in industries. Films formed on the copper surface not only prevent surface corrosion, but also improve its surface morphology ${ }^{20}$.

Recently, investigators have examined the effect of some N-heterocyclic compounds on copper, by changing the placement or the number of substituent groups, and also by inserting heterocyclic compounds, such as triazole, tetrazole, pyrazole and imidazole ${ }^{21-24}$.

The aim of this work was to determine the efficiency of BA and TBA acids as green inhibitors of copper corrosion in a $0.6 \mathrm{~mol} / \mathrm{L} \mathrm{NaCl}$ solution, by using various electrochemical techniques, and also to illustrate the difference between BA and TBA corrosion inhibition performance, studying the temperature effect on the inhibition process and calculating thermodynamic parameters. IR, SEM and EDX analysis were used to correlate the surface with electrochemical behavior.

BA (1, 3-diazinane-2,4,6-trione) and TBA (2-sulfanylidene-1,3-diazinane-4,6dioneare) chemical structures are given in Fig. 1.<smiles>O=C1CC(=O)NC(=O)N1</smiles>

(a)<smiles>O=C1CC(=O)NC(=S)N1</smiles>

(b)

Figure 1. The chemical structures of (a) barbituric acid and (b) thiobarbituric acid. 


\section{Experimental details \\ Materials}

All chemicals were of analytical grade (BDH, Sigma or Aldrich), and were used as-received, without further purification.

\section{Electrochemical measurements}

The working electrode was a copper plate with 99.5 wt $\% \mathrm{Cu}, 0.002$ wt $\% \mathrm{Ni}$, $0.018 \mathrm{wt} \% \mathrm{Al}, 0.005 \mathrm{wt} \% \mathrm{Mn}$ and $0.115 \mathrm{wt} \% \mathrm{Si}$; it was polished with a series of emery papers, then washed with distilled water, and its corrosion potential was measured against $\mathrm{Ag} / \mathrm{AgCl}$, as reference electrode, and pure Pt-wire, as counter electrode. The sodium chloride concentration used as aggressive medium in this work was $0.6 \mathrm{~mol} / \mathrm{L} \mathrm{NaCl}$, with different inhibitors (BA and TBA) concentrations $\left(1 \times 10^{-2}, 5 \times 10^{-3}, 2.5 \times 10^{-3}\right.$ and $\left.1 \times 10^{-3} \mathrm{~mol} / \mathrm{L}\right)$. The electrochemical measurements, such as potentiodynamic polarization and impedance studies, were carried out using a PGSTAT302N Autolab potentiostat/galvanostat. Potentiodynamic polarization curves were studied by changing the electrode potential from $-0.8 \mathrm{~V}$ to $0.2 \mathrm{~V}$, with a potential scan rate of $1 \mathrm{mVs}^{-1}$.

The same procedure of polishing the working electrode was used, immersing it in $0.6 \mathrm{~mol} / \mathrm{L} \mathrm{NaCl}$, with and without inhibitor, at different temperatures $\left(25^{\circ} \mathrm{C}, 35\right.$ ${ }^{\circ} \mathrm{C}, 45^{\circ} \mathrm{C}$ and $55^{\circ} \mathrm{C}$ ), to study their effect. The corrosion parameters, i.e. corrosion current density, $\mathrm{i}_{\text {corr, }}$ and corrosion potential, $\mathrm{E}_{\text {corr, }}$ were evaluated from the intersection of the linear anodic and cathodic branches of the Tafel plots. BA and TBA inhibition efficiency values were calculated according to equation (1).

$$
\mathrm{IE}(\%)=\frac{i_{\text {corr }-i_{\text {corr }}^{o}}^{o}}{i_{\text {corr }}^{o}} \times 100
$$

where $\mathrm{i}_{\text {corr }}^{\mathrm{o}}$ and $\mathrm{i}_{\text {corr }}$ are the uninhibited and inhibited corrosion current densities, respectively. The electrochemical impedance spectroscopy (EIS) of the electrode surface, after its immersion in $0.6 \mathrm{~mol} / \mathrm{L} \mathrm{NaCl}$, with and without inhibitor, has been carried out with an Ac voltage amplitude of $10 \mathrm{mV}$, using an electrochemical impedance system. The frequency range used in the study was $0.02-10^{5} \mathrm{~Hz}$. All the electrochemical impedance measurements were carried out at open circuit potential.

\section{Surface morphology}

The surface morphology of copper specimens, after 3 days of immersion in 0.6 $\mathrm{mol} / \mathrm{LNaCl}$, with and without the optimum inhibitors concentrations (BA: $5 \times 10^{-3}$ mol/L and TBA: $\left.1 \times 10^{-3} \mathrm{~mol} / \mathrm{L}\right)$, was analyzed by a JEOL-JSM-5600 scanning electron microscope equipped with an energy dispersive OXFORD Link-ISIS300 X-ray spectroscopy.

\section{FTIR study}

IR spectra were recorded to assess the power of the two inhibitors and of their film adsorbed onto the copper surface, with the aid of JASCO 4600 model FTIR spectrometer. 


\section{Results and discussion}

\section{Polarization studies}

Copper cathodic and anodic polarization curves in $0.6 \mathrm{~mol} / \mathrm{L} \mathrm{NaCl}$, with and without different BA and TBA concentrations, are shown in Figs. 2 and 3.

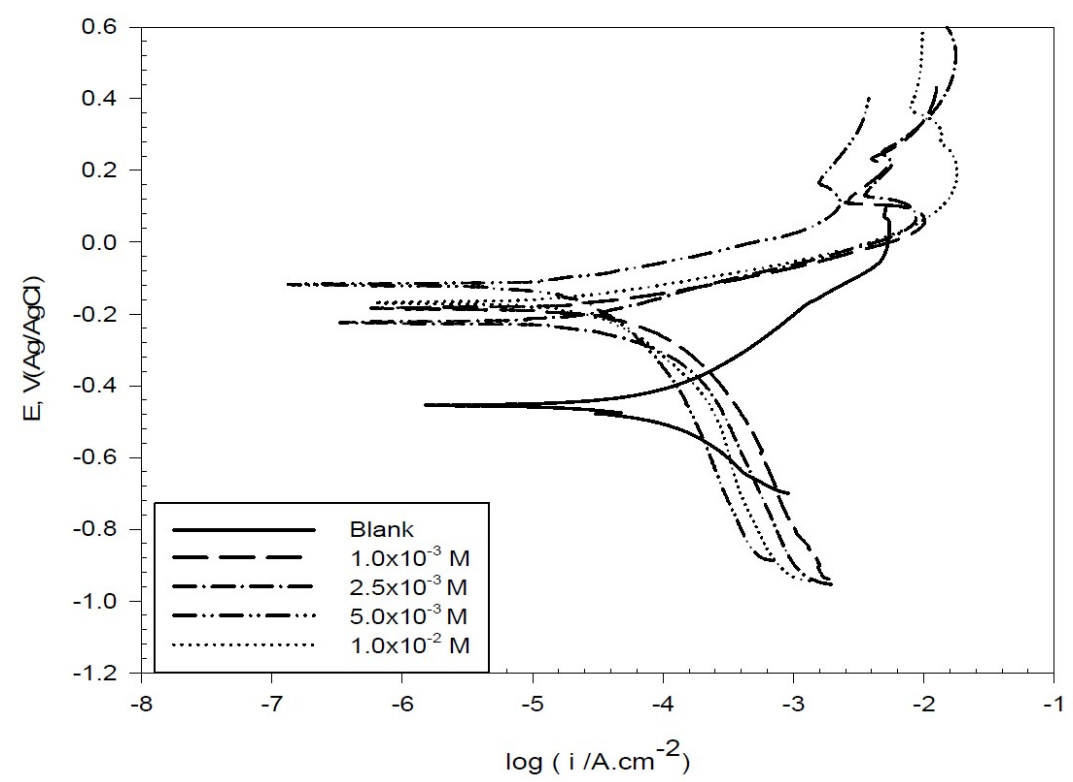

Figure 2. Potentiodynamic polarization curves for copper in $0.6 \mathrm{~mol} / \mathrm{L} \mathrm{NaCl}$, in the absence and presence of different BA concentrations, at $298 \mathrm{~K}$.

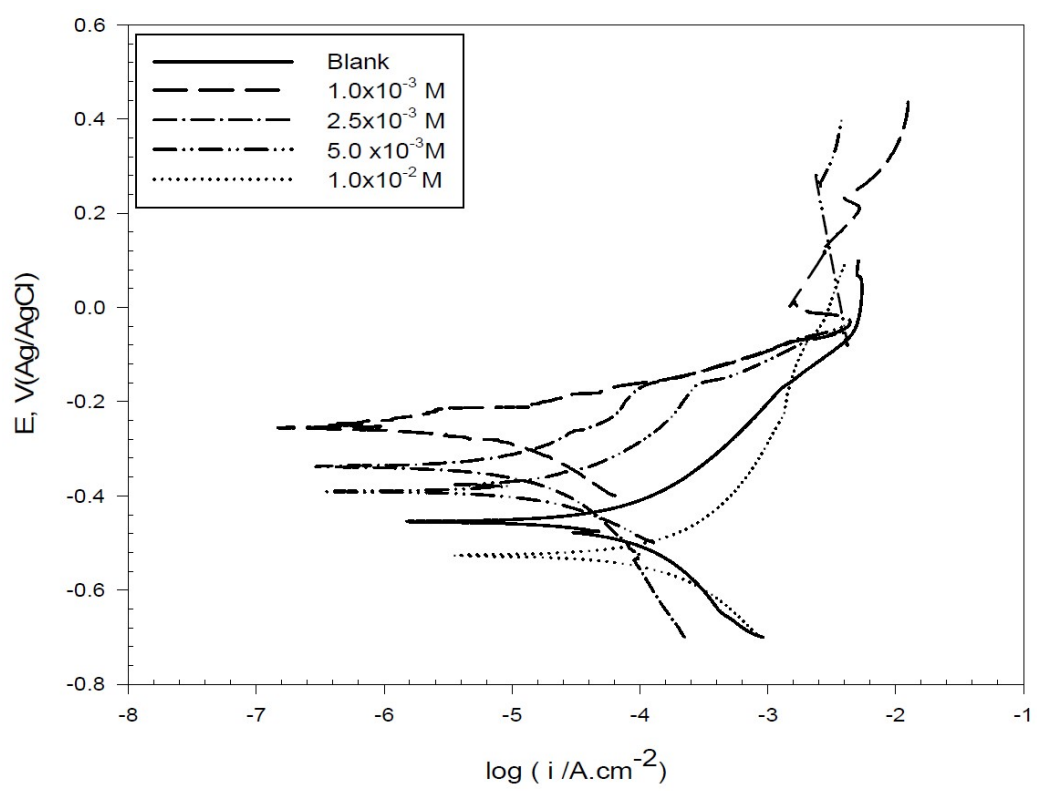

Figure 3. Potentiodynamic polarization curves for copper in $0.6 \mathrm{~mol} / \mathrm{L} \mathrm{NaCl}$, in the absence and presence of different BA concentrations, at $298 \mathrm{~K}$.

The corrosion parameters predicted from Tafel polarization curves are listed in Table 1. It was observed that copper corrosion rate in $0.6 \mathrm{~mol} / \mathrm{L} \mathrm{NaCl}$ decreased in the inhibitors presence. The decrease in the anodic and cathodic current density may be due to the formation of a barrier film on the metal surface, which 
is probably related to the inhibitor molecules adsorption onto the electrode surface, and also to the elevation of hydrogen evolution reaction or oxygenreduction reaction, which prevents the formation of soluble $\mathrm{CuCl}_{2}{ }^{25}$. In other words, at the first region of anodic polarization, the increase in the current density may be caused by the formation of soluble $\mathrm{CuCl}_{2}$ which, after some time, suffers a decrease due to the formation of mainly a $\mathrm{CuCl}$ film, and then again an increase, because of the film dissolution following $\mathrm{Cu}$ (II) ions production ${ }^{26}$. In this study, we notice that the corrosion potential ( $E_{\text {corr }}$ ) changed to less negative values in the inhibitors presence, with an effect on the anodic and cathodic reaction; so, they are mixed type inhibitors ${ }^{27}$.

Table 1. Corrosion parameters obtained from copper polarization curves in $0.6 \mathrm{~mol} / \mathrm{L}$ $\mathrm{NaCl}$, with and without different BA and TBA concentrations, at $298 \mathrm{~K}$.

\begin{tabular}{|c|c|c|c|c|c|c|}
\hline $\begin{array}{c}\text { Solution } \\
\text { type }\end{array}$ & $\begin{array}{c}\text { Conc. } \\
(\mathrm{mol} / \mathrm{L}))\end{array}$ & $\beta_{a}(\mathrm{~V} / \mathrm{dec})$ & $\beta_{\mathrm{c}}(\mathrm{V} / \mathrm{dec})$ & $E_{c o r r}(\mathrm{~V})$ & $\begin{array}{c}I_{\text {corr }} \\
\left(\mathbf{A} / \mathbf{c m}^{2}\right)\end{array}$ & IE\% \\
\hline Blank & - & 0.1423 & 0.1618 & -0.4544 & $1.03 \times 10^{-4}$ & --- \\
\hline \multirow{4}{*}{ BA } & $1.0 \times 10^{-3}$ & 0.0745 & 0.1931 & -0.1791 & $3.6 \times 10^{-5}$ & 64.9 \\
\hline & $2.5 \times 10^{-3}$ & 0.0973 & 0.1780 & -0.2079 & $2.66 \times 10^{-5}$ & 74.1 \\
\hline & $5.0 \times 10^{-3}$ & 0.2101 & 0.0645 & -0.1641 & $1.84 \times 10^{-5}$ & 82.1 \\
\hline & $1.0 \times 10^{-2}$ & 0.0768 & 0.2368 & -0.1641 & $4.06 \times 10^{-5}$ & 60.4 \\
\hline \multirow{4}{*}{ TBA } & $1.0 \times 10^{-3}$ & 0.0515 & 0.0615 & -0.2572 & $2.14 \times 10^{-6}$ & 95.8 \\
\hline & $2.5 \times 10^{-3}$ & 0.1071 & 0.0965 & -0.3387 & $6.56 \times 10^{-6}$ & 93.6 \\
\hline & $5.0 \times 10^{-3}$ & 0.0670 & 0.0541 & -0.3891 & $6.69 \times 10^{-6}$ & 86.9 \\
\hline & $1.0 \times 10^{-2}$ & 0.1457 & 0.1272 & 0.5289 & $8.98 \times 10^{-5}$ & 12.5 \\
\hline
\end{tabular}

The preferential adsorption of these compounds plays an important role in blocking the active sites, in both anodic and cathodic reactions, which leads to the protection of part of the surface against the aggressive attack $^{28}$. This adsorption results in the formation of a protective complex with copper ions, and it can be described as the following mechanism ${ }^{29}$.

$$
\mathrm{Cu}_{(\mathrm{S})}+\mathrm{BA}_{(\mathrm{aq})} \rightarrow \mathrm{Cu}: \mathrm{BA}_{(\mathrm{ads})}+\mathrm{H}_{(\mathrm{aq})}^{+}
$$

Noticeably, TBA inhibition efficiency values are higher than those of BA. This may be related to the molecular structure of the inhibitor which gives or accepts electrons to or from the metal surface, leading to new bonds ${ }^{30}$, and also due to the replacement of one oxygen atom in BA by one sulfur atom in TBA. The direction of the inhibitor molecule is substantial, enabling to build up a stronger bond, due to the interaction of the ring's $\pi$-electrons with copper's empty $d$ orbitals, in a parallel orientation of the inhibitor molecule ${ }^{31}$.

\section{Impedance studies}

EIS is a useful tool for studying the electrode surface behavior, and predicting the corrosion rate. The Nyquist plots $\left(Z-Z^{\prime}\right)$ of the copper electrode in $0.6 \mathrm{~mol} / \mathrm{L}$ $\mathrm{NaCl}$, without and with different BA and TBA concentrations, at open circuit conditions, are shown in Figs. 4 and 5. 
It is apparent that the diameter of the Nyquist plot approximately amounts to the resistance value during the corrosion process. The diameter increased with higher BA concentrations, until these reached $5 \times 10^{-3} \mathrm{~mol} / \mathrm{L}$; then, it decreased again with increased concentrations up to $1 \times 10^{-2} \mathrm{~mol} / \mathrm{L}$.

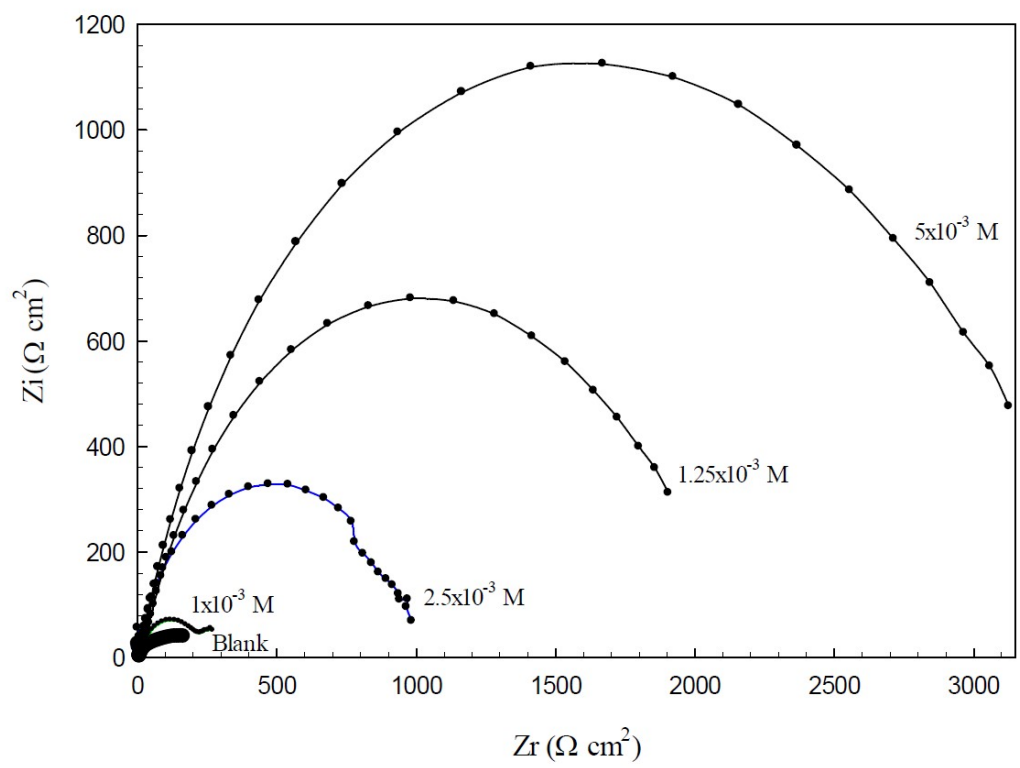

Figure 4. Nyquist plots for copper in $0.6 \mathrm{~mol} / \mathrm{L} \mathrm{NaCl}$, with various $\mathrm{BA}$ concentrations, at $298 \mathrm{~K}$.

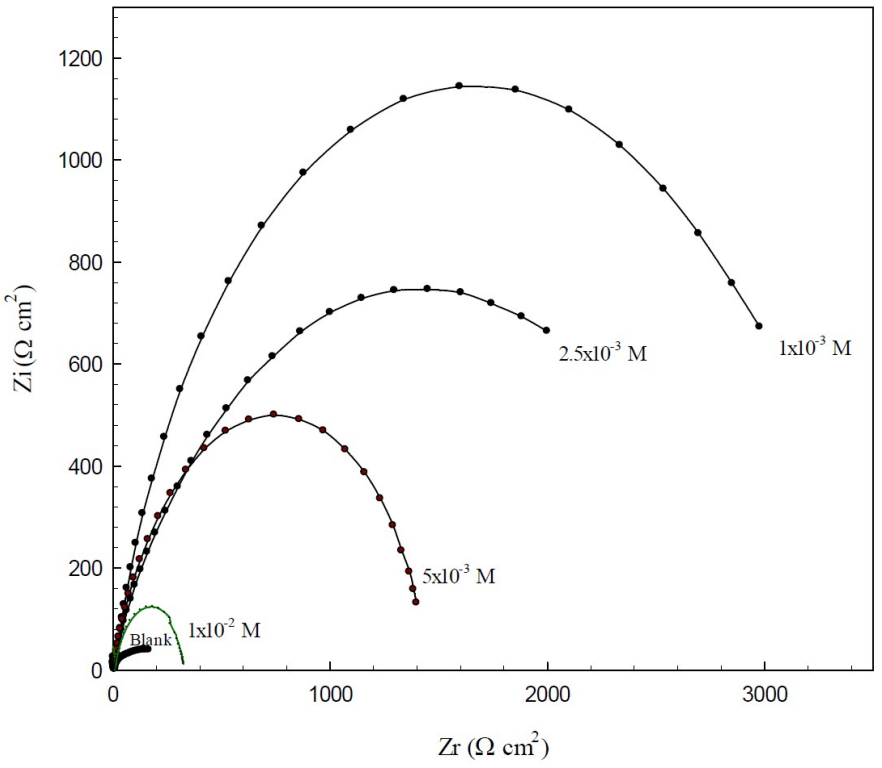

Figure 5. Nyquist plots for copper in $0.6 \mathrm{~mol} / \mathrm{L} \mathrm{NaCl}$, with various TBA concentrations, at $298 \mathrm{~K}$.

For TBA, the highest diameter was at $1 \times 10^{-3} \mathrm{~mol} / \mathrm{L}$ concentration; then, the diameter decreased with higher concentrations. These results indicate the gradual substitution of water molecules by the adsorption of organic molecules at the copper/solution interface, until optimum concentrations ${ }^{32}$. The decrease in the resistance at higher TBA concentrations may be due to the accumulation of the 
inhibitor molecules at the metal surface, which results in the retarding of the adsorption process. So, BA and TBA can act as corrosion inhibitors, and the highest efficiency is at the optimum concentrations for each one.

The Bode plots $(\log Z-\log \mathrm{f})$ are presented in Figs. 6 and 7. Symbols in these figures represent the measured data, and solid lines represent the fitting data obtained using the most suitable equivalent circuit.

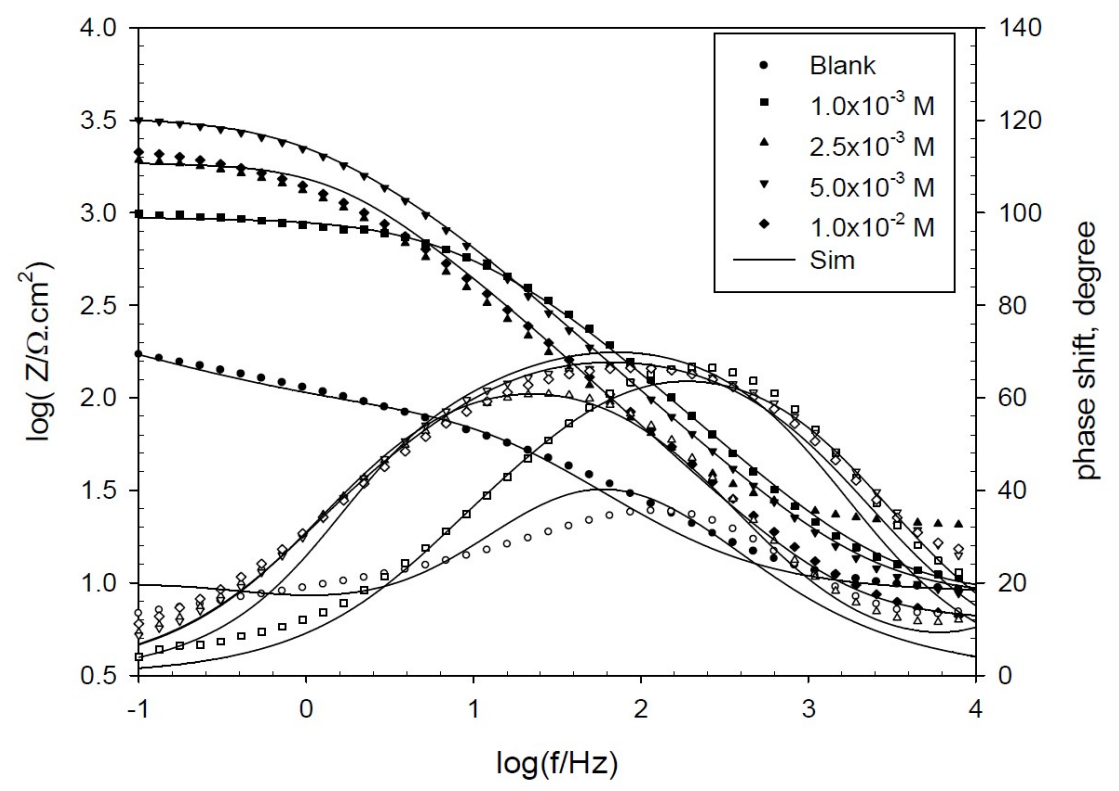

Figure 6. Bode plots for copper in $0.6 \mathrm{~mol} / \mathrm{L} \mathrm{NaCl}$, in the absence and presence of various BA concentrations, at $298 \mathrm{~K}$.

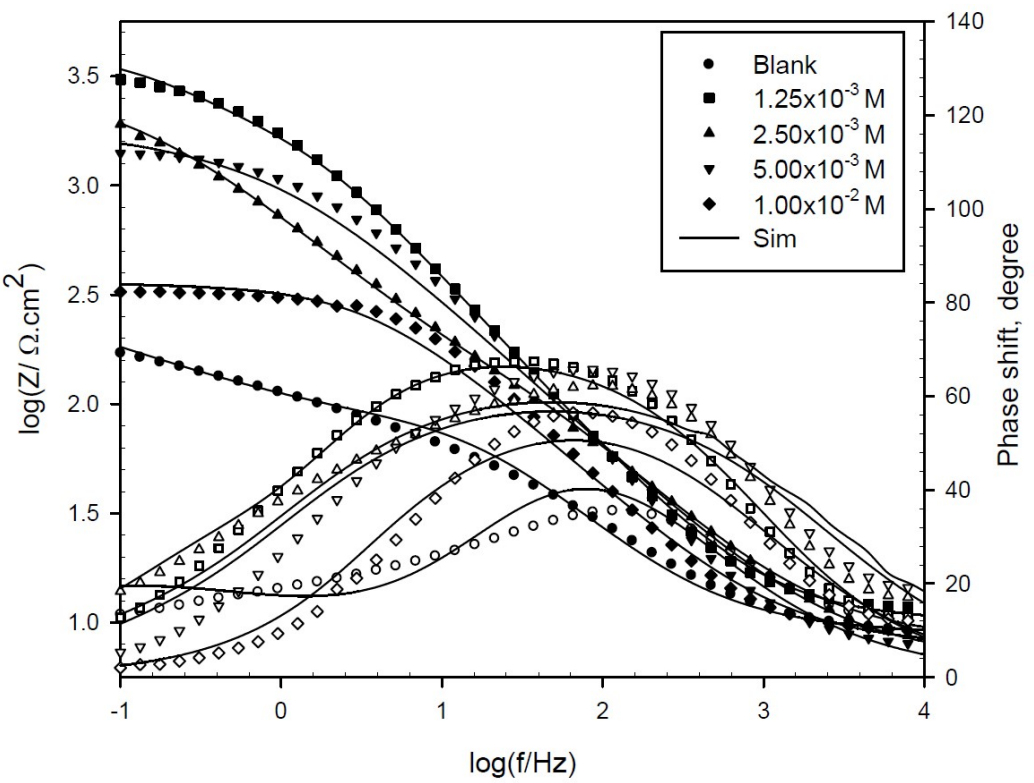

Figure 7. Bode plots for copper in $0.6 \mathrm{~mol} / \mathrm{L} \mathrm{NaCl}$, in the absence and presence of various TBA concentrations, at $298 \mathrm{~K}$.

The Bode plots show a resistive region at high frequencies, a capacitive region at intermediate frequencies and another resistive region at low frequencies. From the horizontal plateau region at high frequency, $\mathrm{R}_{\mathrm{s}}$ value can be obtained, which 
is almost constant with different inhibitor concentrations. However, polarization resistance varied with the inhibitor concentrations, and it could be obtained from the plateau at low frequency.

The phase plots $(\theta-\log \mathrm{f})$ show peaks' shape and maximum angle at an intermediate frequency, and the blank shows an angle at $35^{\circ}$ which increased to $68^{\circ}$ and $70^{\circ}$, at optimum BA and TBA concentrations, respectively, suggesting higher corrosion resistance. At the low frequency region, the peak of the phase angle plot becomes broad, indicating an interaction of, at least, two time constants.

This result can reveal that there is more than one occurred electrochemical process, and the growth of more resistive BA and TBA layers adsorbed onto the copper surface, forming complex $\mathrm{CuBA}$ and $\mathrm{CuTBA}$ protected films.

All the experimental results investigated by using the equivalent circuit are shown in Fig. 8. $\mathrm{R}_{\mathrm{s}}$ (solution resistance) is in series with two circuits, including $\mathrm{R}_{1}(\mathrm{CPE})_{1}$ and $\mathrm{R}_{2}(\mathrm{CPE})_{2}$, with parallel connections which are suitable for the electrochemical properties of the bi-layered surface film.

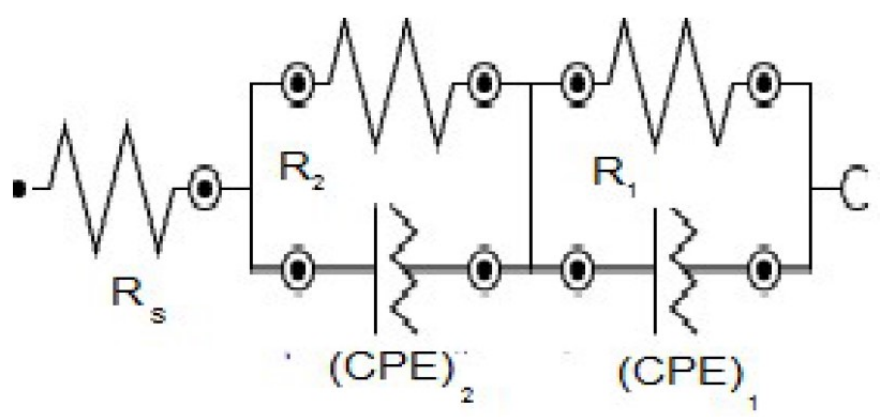

Figure 8. Equivalent circuit used to fit the EIS parameters.

The resistance of the compact inner layer $\left(\mathrm{R}_{1}\right)$ is higher than that from the outer porous layer resistance $\left(\mathrm{R}_{2}\right)$. CPE is the constant phase element which displays the double layer and represents the most suitable factor, to observe the thickness of the protective film. CPE is used in place of the ideal capacitance, due to the surface's poor homogeneity. $\mathrm{CPE}\left(\mathrm{Z}_{\mathrm{CPE}}\right)$ impedance was obtained from equation 2.

$$
Z_{\mathrm{CPE}}=1 / \mathrm{Y}_{\mathrm{o}}(\mathrm{j} \omega)^{\mathrm{n}}
$$

where $Y_{o}$ is the CPE modulus, which refers to the formed film capacitance, $\omega$ is the radial frequency, $\mathrm{j}$ is the imaginary root and $\mathrm{n}$ is the phase shift, and its value varies between 1, for the ideal capacitor, and less than 1 for the porous surface $^{33,34}$. The inhibition efficiency was calculated using equation 3:

$$
\text { IE } \%=\frac{R_{\text {inh }}-R}{R_{\text {inh }}} X 100
$$

where $\mathrm{R}$ and $\mathrm{R}_{\text {inh }}$ are the charge transfer resistances in the inhibitor absence and presence.

The calculated efficiency and the measured EIS parameters for adsorbed BA and TBA onto the copper surface are listed in Table 2 . It can be noticed that $R_{1}$ and 
$\mathrm{R}_{2}$ values increased with increasing BA concentrations, and decreased with TBA concentrations, until they reached optimum values. $\mathrm{CPE}_{1}$ and $\mathrm{CPE}_{2}$ values decreased, and the deviations of the phase shift were lower than the ideal value (unity), as a result of the surface irregularities and inhomogeneity ${ }^{35}$, which also may be due to the surface coverage by the adsorbed molecules at the copper/solution interface. According to the above results, BA and TBA can be used as good inhibitors for copper in a $\mathrm{NaCl}$ solution, and TBA is more effective than BA, due to the sulfur atom presence ${ }^{36}$.

The results obtained from the impedance studies are in good agreement with those obtained from the polarization studies.

Table 2. Impedance parameters for copper acquired from plots in a $0.6 \mathrm{~mol} / \mathrm{L} \mathrm{NaCl}$ solution, in the absence and presence of different BA and TBA concentrations.

\begin{tabular}{|c|c|c|c|c|c|c|c|c|c|}
\hline \multirow{2}{*}{$\begin{array}{c}\text { Solution } \\
\text { type }\end{array}$} & \multirow{2}{*}{$\begin{array}{c}\text { Conc. } \\
(\mathrm{mol} / \mathrm{L})\end{array}$} & \multirow{2}{*}{$\begin{array}{l}\mathbf{R}_{\mathbf{s}} \\
\mathbf{\Omega}\end{array}$} & \multirow{2}{*}{$\begin{array}{c}\mathbf{R}_{2} \\
\mathbf{\Omega} \mathrm{cm}^{2}\end{array}$} & \multicolumn{2}{|c|}{$(\mathrm{CPE})_{2}$} & \multirow{2}{*}{$\begin{array}{c}\mathbf{R}_{1} \\
\mathbf{\Omega} \mathrm{cm}^{2}\end{array}$} & \multicolumn{2}{|c|}{$(\mathrm{CPE})_{1}$} & \multirow[t]{2}{*}{ IE\% } \\
\hline & & & & $\begin{array}{c}\mathbf{Y}_{0}, \\
\mu \Omega^{-1} \mathbf{c m}^{-2}\end{array}$ & n & & $\begin{array}{c}Y_{0}, \\
\mu \Omega^{-1} \mathbf{c m}^{-2}\end{array}$ & $\mathbf{n}$ & \\
\hline Blank & - & 8.72 & 68 & 620 & 0.50 & 175 & 490 & 0.80 & - \\
\hline \multirow{4}{*}{ BA } & $1.0 \times 10^{-3}$ & 6.71 & 126 & 70 & 0.70 & 810 & 339 & 0.90 & 78.4 \\
\hline & $2.5 \times 10^{-3}$ & 15.97 & 130 & 68 & 0.90 & 1656 & 319 & 0.62 & 89.4 \\
\hline & $5.0 \times 10^{-3}$ & 8.29 & 250 & 64 & 0.80 & 3050 & 152 & 0.90 & 94.2 \\
\hline & $1.0 \times 10^{-2}$ & 6.20 & 200 & 91 & 0.90 & 1665 & 210 & 0.80 & 89.5 \\
\hline \multirow{4}{*}{ TBA } & $1.0 \times 10^{-3}$ & 8.25 & 3491 & 260 & 0.72 & 953.6 & 120 & 0.90 & 94.0 \\
\hline & $2.5 \times 10^{-3}$ & 6.20 & 2885 & 380 & 0.68 & 69.7 & 250 & 0.75 & 93.0 \\
\hline & $5.0 \times 10^{-3}$ & 8.10 & 2290 & 410 & 0.60 & 69.88 & 350 & 0.90 & 92.0 \\
\hline & $1.0 \times 10^{-2}$ & 10.06 & 290 & 420 & 0.67 & 69.88 & 520 & 0.90 & 40.0 \\
\hline
\end{tabular}

\section{Adsorption isotherm}

Generally, the investigation of adsorption processes is determined by adsorption isotherms that provide structural information about the linkage between the additive inhibitor and the metal surface which results in the retardation of the corrosion rate by weakening the diffusion of corrosive species, or by increasing the metal surface resistance. Flory-Huggins isotherm was the best suitable model that fitted the experimental data which were used to describe BA and TBA adsorption characteristics onto the copper surface, in a $0.6 \mathrm{~mol} / \mathrm{L} \mathrm{NaCl}$ solution.
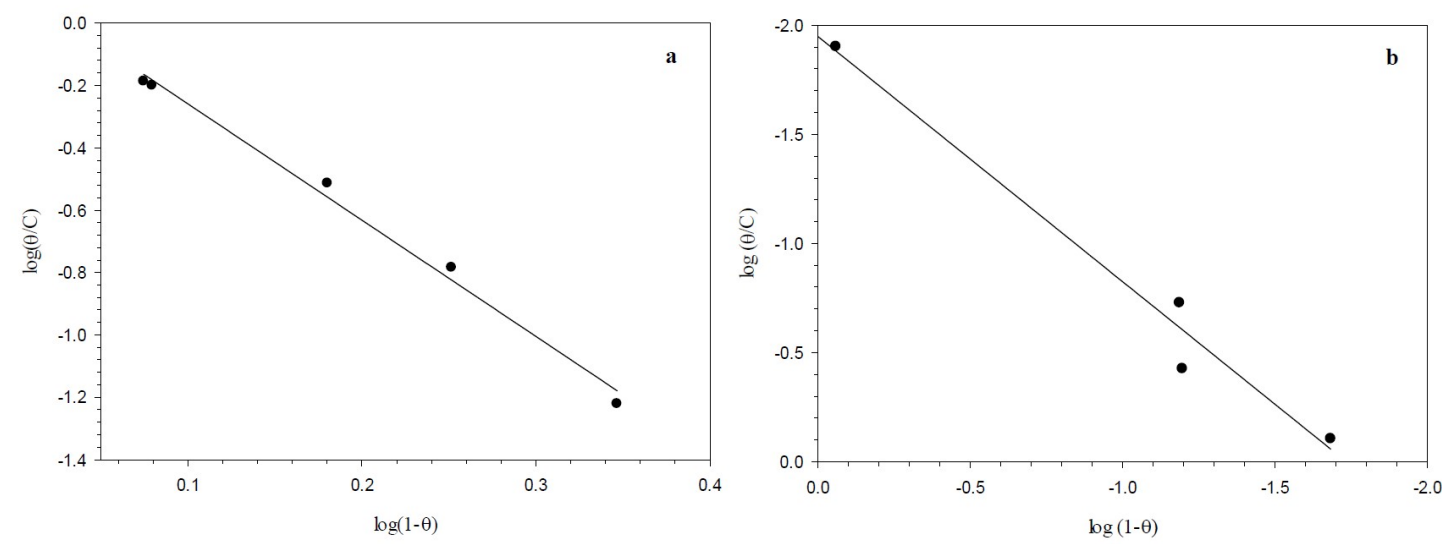

Figure 9. Linear relationship of the Flory-Huggins model for the adsorption of (a) BA and (b) TBA onto the copper surface, in $0.6 \mathrm{~mol} / \mathrm{L} \mathrm{NaCl}$, at $298 \mathrm{~K}$. 
Fig. 9 offers the linear representation of the function $\log \frac{\theta}{c_{o}}$ against $\log (1-\theta)$, according to Flory-Huggins equation ${ }^{37}$, which is expressed by equation 4 .

$$
\log \frac{\theta}{C_{o}}=\log K_{F H}+n \log (1-\theta)
$$

where $\mathrm{n}$ is the number of ions occupying adsorption sites, $\mathrm{K}_{\mathrm{FH}}$ is the equilibrium constant $\left(\mathrm{L} \mathrm{mol}^{-1}\right), \mathrm{C}_{\mathrm{o}}$ is the equilibrium concentration and $\theta$ is the surface coverage degree. The regression coefficient $\left(\mathrm{R}^{2}\right)$ values nearly close to one proved that BA and TBA adsorption onto the copper surface obeyed FloryHuggins isotherm. In addition, the equilibrium constant $\left(\mathrm{K}_{\mathrm{FH}}\right)$ values obtained from this isotherm and the change in the standard free energy $\left(\Delta \mathrm{G}^{\mathrm{o}}\right)$ of adsorption can be specified according to equation 5 , and are listed in Table 3 .

$$
K_{F H}=\exp \left(\frac{-\Delta G^{o}}{R T}\right)
$$

where $\mathrm{R}$ is the universal gas constant $\left(8.314 \mathrm{~mol}^{-1} \mathrm{~K}^{-1}\right)$ and $\mathrm{T}$ is the absolute temperature. The adsorption processes are always classified into chemisorption or physisorption, according to $\Delta \mathrm{G}^{0}$ values ${ }^{38}$. Chemisorption occurs when $\Delta \mathrm{G}^{\mathrm{o}}$ is equal to or more negative than $40 \mathrm{kJmol}^{-1}$, where the charge shared or transferred from the inhibitor molecules to the copper surface forms a coordinate covalent bond. Physisorption occurs when $\Delta \mathrm{G}^{\circ}$ is equal to or less negative than $-20 \mathrm{kJmol}^{-}$ 1 , in which an electrostatic interaction between charged molecules and charged metal surface is considered.

According to Table 3, $\Delta \mathrm{G}^{\mathrm{o}}$ values are in between -20 and $-40 \mathrm{kJmol}^{-1}$, which indicates that the inhibitor molecules adsorption included a mixed-type physisorption and chemisorption mechanism ${ }^{39}$.

Table 3. Flory-Huggins data determined from regression equations for the adsorption of BA and TBA acids at optimum concentration, at $298 \mathrm{~K}$.

\begin{tabular}{|c|c|c|c|c|c|}
\hline Inhibitors & $\begin{array}{c}\text { Conc. } \\
(\mathbf{m o l} / \mathbf{L})\end{array}$ & $\mathbf{R}^{\mathbf{2}}$ & $\mathbf{N}$ & $\mathbf{K}_{\mathbf{F H}}$ & $\boldsymbol{\Delta \mathbf { G }}^{\mathbf{0}} \mathbf{( \mathbf { K J m o l } ^ { - \mathbf { 1 } } )}$ \\
\hline BA & $5 \times 10^{-3}$ & 0.9984 & -3.7 & 1298 & -27.71 \\
\hline TBA & $1 \times 10^{-3}$ & 0.9892 & -1.1 & 11.27 & -15.95 \\
\hline
\end{tabular}

\section{Effect of temperature}

Activation variables for the adsorption features of the studied compounds on copper in $0.6 \mathrm{~mol} / \mathrm{L} \mathrm{NaCl}$ were calculated by supposing a direct relationship between the $\log$ of $i_{\text {corr }}$ (the rate constant for the corrosion reaction) and $1 / T$, according to the Arrhenius pattern, as in equation 6:

$$
\log i_{\text {corr }}=\log A-\frac{E_{a}}{2.303 R T}
$$

where $\mathrm{A}$ is the frequency factor, $\mathrm{R}$ is the universal gas constant and $\mathrm{T}$ is the absolute temperature. The relationship between the $\log$ of $\mathrm{i}_{\text {corr }}$ and $1 / \mathrm{T}$ presented straight lines with good degree of linearity, as shown in Fig. 10. 


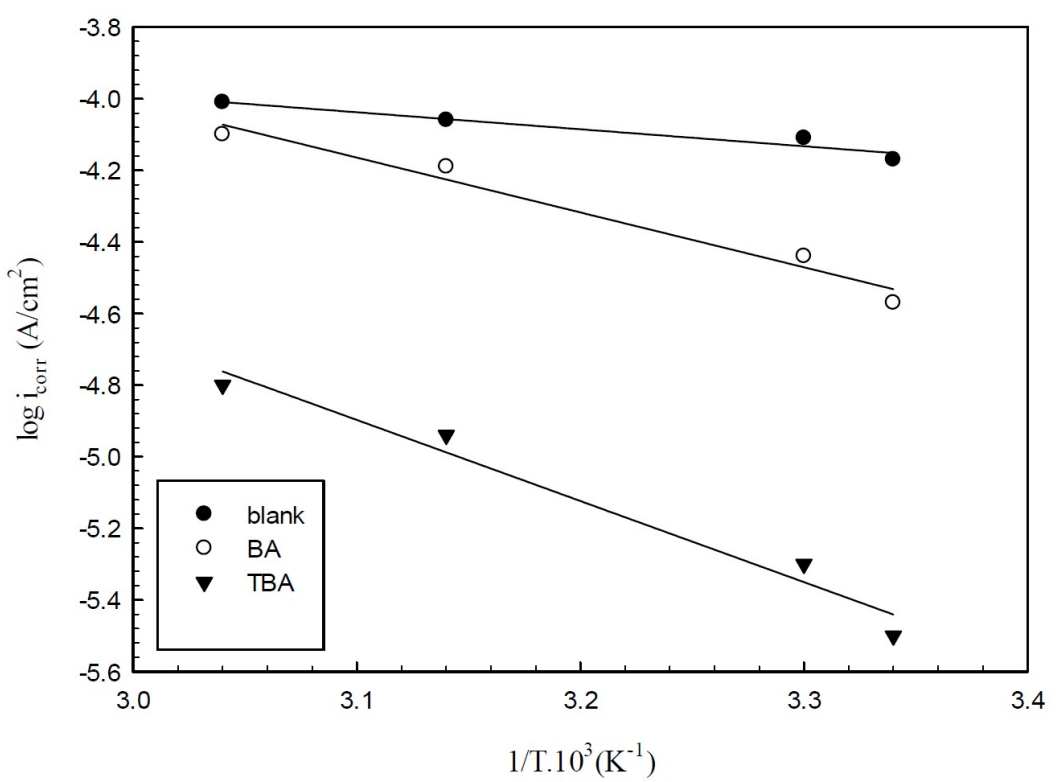

Figure 10. Arrhenius plots for corrosion copper in $0.6 \mathrm{~mol} / \mathrm{L} \mathrm{NaCl}$, in the presence and absence of inhibitors.

The activation energies concluded from the plots of copper immersed in 0.6 $\mathrm{mol} / \mathrm{L} \mathrm{NaCl}$, without and with optimum concentrations of BA and TBA, are listed in Table 4.

Table 4. Thermodynamic parameters for the adsorption at optimum concentrations of inhibitor molecules onto the copper surface in $0.6 \mathrm{~mol} / \mathrm{L} \mathrm{NaCl}$, at different temperatures.

\begin{tabular}{|c|c|c|c|c|c|}
\hline Inhibitors & $\begin{array}{l}\text { Conc. } \\
(\mathrm{mol} / \mathrm{L})\end{array}$ & $\mathbf{T}(\mathbf{K})$ & $\begin{array}{c}\mathbf{E}_{\mathrm{a}} \\
(\mathrm{J} / \mathrm{mol})\end{array}$ & $\begin{array}{c}\Delta \mathbf{H}^{*} \\
(\mathrm{~J} / \mathrm{mol})\end{array}$ & $\begin{array}{c}\Delta \mathbf{S}^{*} \\
(\mathrm{~J} / \mathrm{mol} \mathbf{K})\end{array}$ \\
\hline \multirow{4}{*}{ Blank } & \multirow{4}{*}{-} & 298 & 2.71 & -7.80 & \multirow{4}{*}{-237.95} \\
\hline & & 308 & 2.81 & -8.06 & \\
\hline & & 318 & 2.88 & -8.32 & \\
\hline & & 328 & 2.98 & -8.59 & \\
\hline \multirow{4}{*}{ BA } & \multirow{4}{*}{$5 \times 10^{-3}$} & 298 & 8.74 & 9.69 & \multirow{4}{*}{-52.77} \\
\hline & & 308 & 9.03 & 10.01 & \\
\hline & & 318 & 9.32 & 10.34 & \\
\hline & & 328 & 9.62 & 10.66 & \\
\hline \multirow{4}{*}{ TBA } & \multirow{4}{*}{$1 \times 10^{-3}$} & 298 & 12.92 & 17.61 & \multirow{4}{*}{19.52} \\
\hline & & 308 & 13.35 & & \\
\hline & & 318 & 13.97 & 18.79 & \\
\hline & & 328 & 14.22 & 19.39 & \\
\hline
\end{tabular}

$E_{a}$ values for the inhibited copper are higher than those for the uninhibited one, due to the adsorption of inhibitor molecules onto the active sites on the copper surface, which increases the energy barrier connected with the corrosion reaction. Also, the increase in activation energy may be explained as a result of the physical adsorption that happens at the first step, which is proved by decreasing the inhibition efficiency with an increasing temperature ${ }^{40-43}$. 


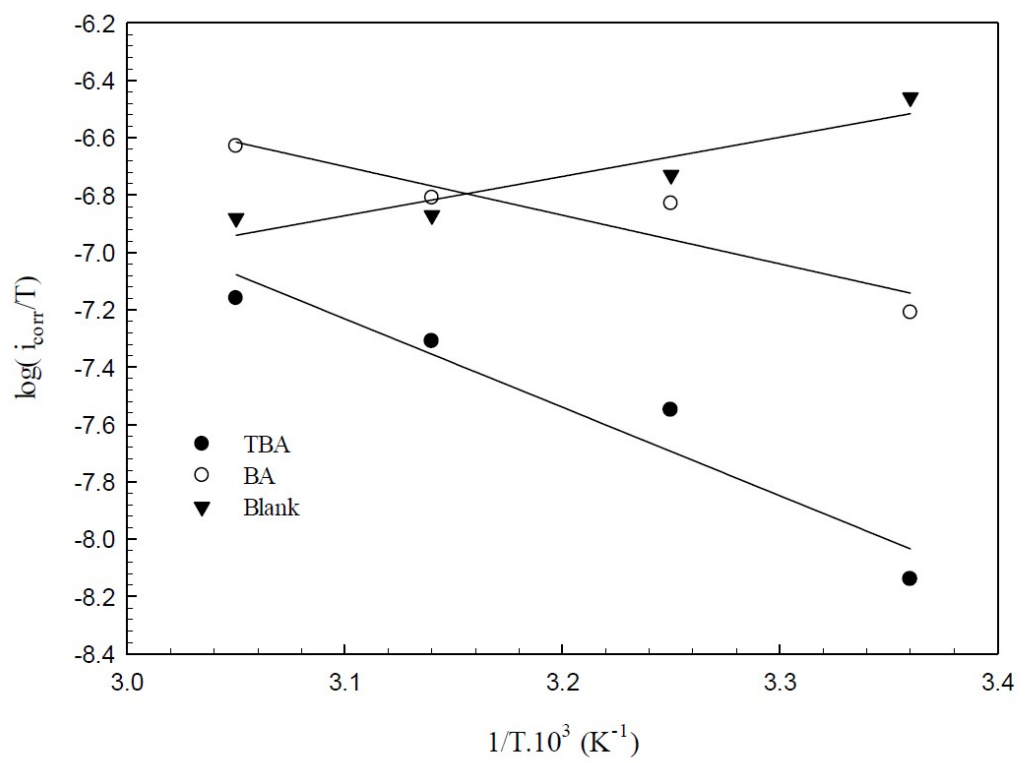

Figure 11. Transition state plots for copper in $0.6 \mathrm{~mol} / \mathrm{L} \mathrm{NaCl}$ at $5 \times 10^{-3} \mathrm{~mol} / \mathrm{L}$ of $\mathrm{BA}$ and $1 \times 10^{-3} \mathrm{~mol} / \mathrm{L}$ of TBA, at different temperatures.

Fig. 11 presents the plots of $\log \mathrm{i}_{\text {corr }} / \mathrm{T}$ versus $1 / \mathrm{T}$, depending on the transition state (equation 7).

$$
\log \left(\frac{i_{\text {corr }}}{T}\right)=\left[\left(\log \left(\frac{R}{N h}\right)\right)+\left(\frac{\Delta S^{*}}{2.303 R}\right)\right]-\frac{\Delta H^{*}}{2.303 R T}
$$

where $\mathrm{N}$ is Avogadro's number and $\mathrm{h}$ is the Plank constant. This relationship gives straight lines with the slope and the intercept equal to $\Delta \mathrm{H}^{*} / 2.303 \mathrm{R}$ and $\log \left(\frac{R}{N h}\right)+\Delta \mathrm{S}^{*} / 2.303 \mathrm{R}$, respectively. $\Delta \mathrm{S}^{*}$ and $\Delta \mathrm{H}^{*}$ values are listed in Table 4.

\section{FTIR Spectral Studies}

Different functional groups for the corrosion product on copper in the presence of BA and TBA were realized from FTIR spectra in Fig. 12, which clarifies the difference between the spectra of the adsorbed inhibitors and that of the pure ones. That was noticeable from the shifting of the wavenumber from higher to lower values. The spectra of pure BA and its adsorbed inhibitor display that the broad peaks corresponding to $v(\mathrm{OH})$ and $v(\mathrm{NH})$ in pure BA were sharp in nature, with $\mathrm{CuBA}$ suffering a shift from its position to a lower value for $v(\mathrm{OH})$ group $\left(3500-3310 \mathrm{~cm}^{-1}\right)$ and a higher value for $v(\mathrm{NH})$ group $\left(3244-3277 \mathrm{~cm}^{-1}\right)$.

The stretching of the $\mathrm{CH}$ group in BA was $2900 \mathrm{~cm}^{-1}$, exhibiting a lower wave number, $2844 \mathrm{~cm}^{-1}$, for the BA adsorbed onto the copper surface. Also, the peaks around 1780 and $1678 \mathrm{~cm}^{-1}$, which are assigned to $v(\mathrm{C}=\mathrm{O})$, undergo a shift to lower wavenumbers after adsorption onto the metal surface, i.e., 1733 and 1644 $\mathrm{cm}^{-1}$. This may be due to the covalent bonding of the carbonyl group to the empty hybrid orbital of the copper atom ${ }^{44}$. This description confirmed the ability of the inhibitor molecules to coordinate with $\mathrm{Cu}^{2+}$ ions. 

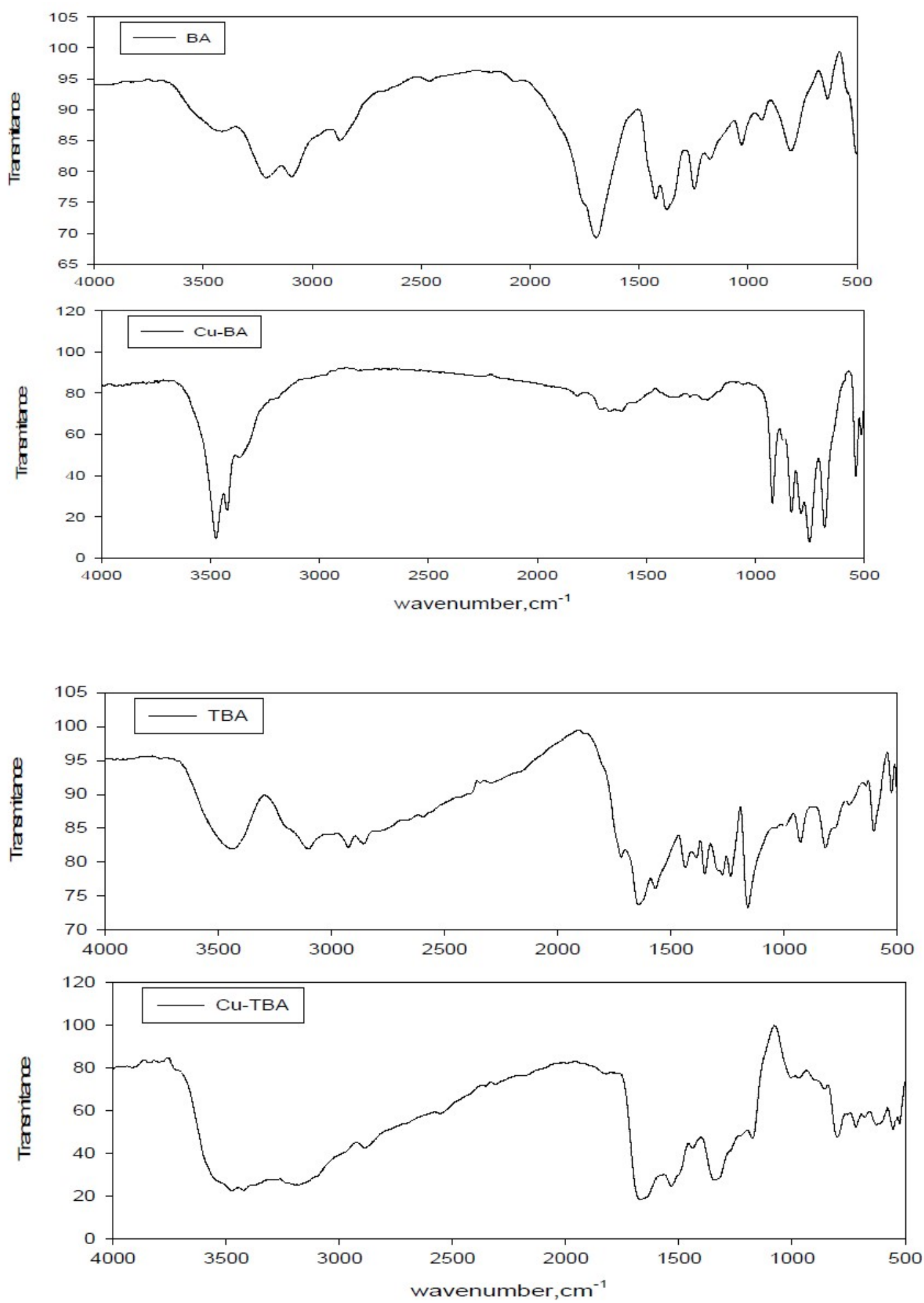

Figure 12. FTIR spectra of pure barbituric acid (BA) and pure thiobarbituric acid (TBA), with $\mathrm{Cu}-\mathrm{BT}$ and $\mathrm{Cu}-\mathrm{TBA}$ films formed at the copper electrode.

The same shifting appears in the FTIR spectrum of TBA. The occurrence of peaks with sharp nature at wavenumbers $955,877,833$ and $778 \mathrm{~cm}^{-1}$ pointed to a metal- ligand bond of BA and TBA chemisorption on the copper surface ${ }^{45}$. 
The characteristic band of $(\mathrm{C}=\mathrm{O})$ group of TBA, adsorbed onto the copper surface, appears at the same wavenumber of pure TBA at 1706 and $1666 \mathrm{~cm}^{-1}$, but has a shape of medium peaks comparing to the weak peaks for pure TBA.

The observed weak peak at $1350 \mathrm{~cm}^{-1}$ in the TBA spectrum assigned to $v(C=S)+$ $v(\mathrm{NH})$ shifted to a higher wavenumber, $1392 \mathrm{~cm}^{-1}$, that can be related to specific molecular interactions, thus leading to the formation of a coordination bond between the sulfur hetero atom and the unfilled d-orbital of the copper atom ${ }^{46}$.

\section{Surface Morphology Investigation (SEM/EDX)}

Scanning electron microscopy (SEM) and energy dispersive X-ray (EDX) spectroscopy is one of the most ordinarily techniques for assessing and analyzing the surface and elemental constituents of corrosion products attached samples. SEM images illustrated the interaction between metals and the corrosive media, so the morphology of the metal surface and collection of corrosion products can be determined by SEM analysis. Fig. 13 exhibits the SEM micrograph of copper specimens after 4 hours of immersion in $0.6 \mathrm{~mol} / \mathrm{L} \mathrm{NaCl}$, in the presence and absence of the studied inhibitors.

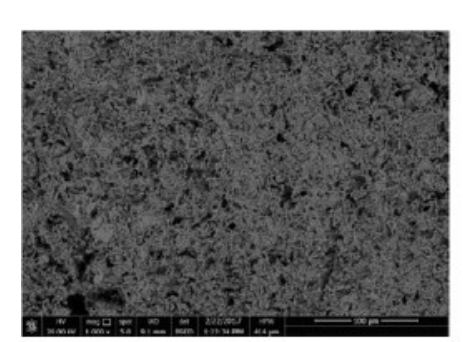

Without inhibitor, at $1000 \mathrm{x}$ magnification.

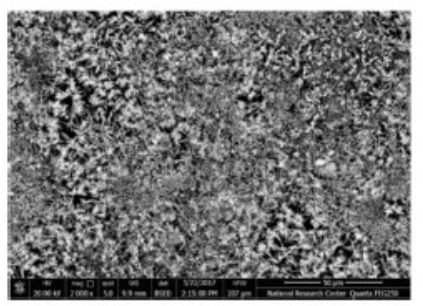

With TBA, at $2000 \mathrm{x}$ magnification. Without inhibitor, at $4000 \mathrm{x}$ magnification.

With BA, at $1000 \times$ magnification

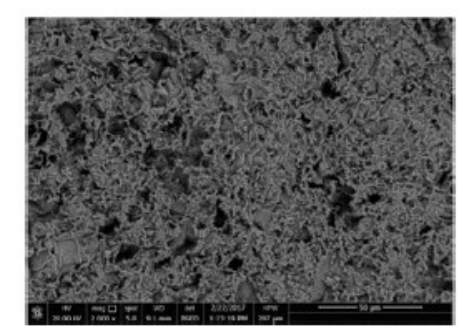

Without inhibitor, at $2000 \mathrm{x}$ magnification.
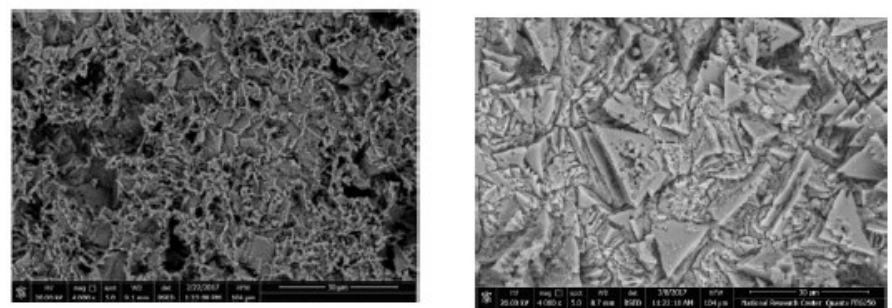

With BA, at $4000 \mathrm{x}$ magnification.

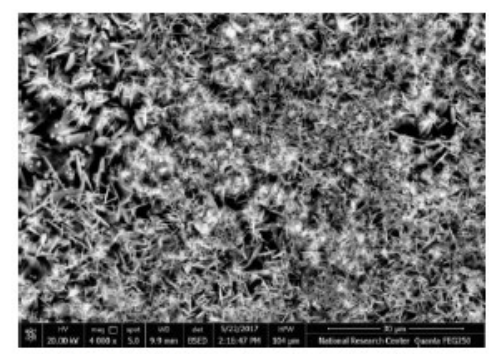

With TBA at $4000 \mathrm{x}$ magnification.

Figure 13. SEM images of the copper corrosion product in $0.6 \mathrm{~mol} / \mathrm{L} \mathrm{NaCl}$, in the presence and absence of inhibitors, at various magnifications.

The copper sample surface in the solution without inhibitor is strongly deteriorated, which is related to its direct attack by aggressive ions. In their turn, the SEM images of copper specimens with the best concentrations of TBA and 
BA offer relatively smoother surfaces, which is due to the adsorption of the inhibitor molecules onto the metallic surface. The protection of the metallic surface occurred by the surface isolation from the corrosive medium, leading to a less damaged and smoother surface.

The EDX spectra of copper surfaces are shown in Fig. 14.
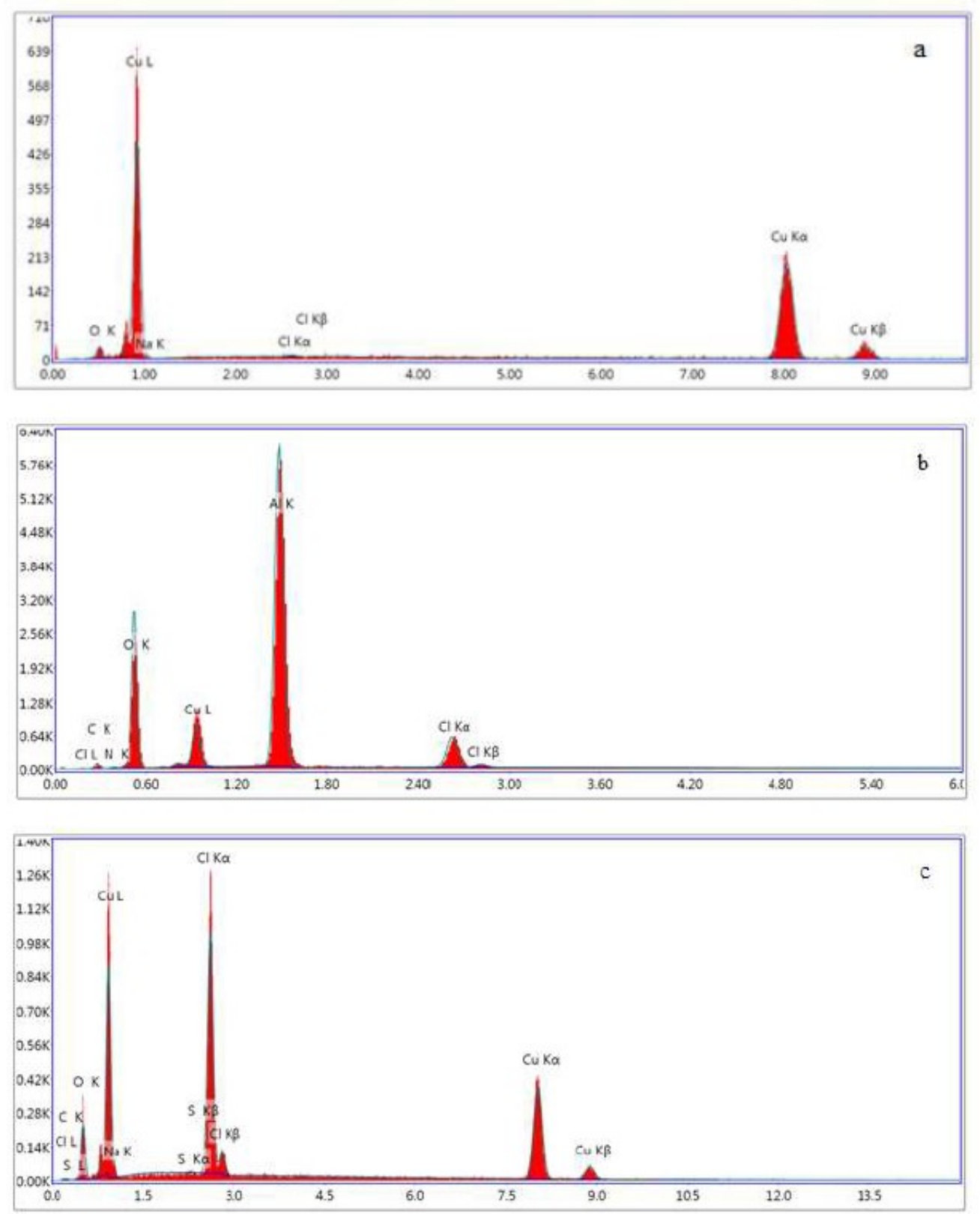

Figure 14. (a) EDX spectra of the uninhibited copper surface, (b) inhibited with BA (c) inhibited with BA and TBA.

It is obvious that the intensity of oxygen in the EDX spectrum of the blank copper sample related to the formation of an oxide film on the surface. By comparing the intensity of oxygen in the EDX spectra of copper surfaces in the presence and absence of inhibitors, its increasing intensity in BA presence was noticeable, which indicates that the adsorption of inhibitor molecules onto the 
copper surface occurred. The presence of nitrogen and sulfur in the EDX spectra of copper obtained from the TBA inhibitor containing solutions definitely testify the adsorption of inhibitors onto the metallic surface.

\section{Conclusions}

Barbituric (BA) and thiobarbituric (TBA) acids act as mixed-type inhibitors, impeding both the anodic and cathodic reactions on copper corrosion in a 0.6 $\mathrm{mol} / \mathrm{L} \mathrm{NaCl}$ solution. The inhibition efficiencies are $95.8 \%$ and $86.9 \%$, in the order of TBA $>$ BA, at optimum concentrations of $1 \times 10^{-3} \mathrm{~mol} / \mathrm{L}$ and $5 \times 10^{-3}$, respectively.

The adsorption process of these inhibitors obeyed Flory-Huggins isotherm, seeming to follow physisorption and chemisorption modes. IR studies and morphology analysis (SEM and EDX) manifested the results obtained from electrochemical techniques.

\section{References}

1. Volkan C. Corrosion Chemistry. New Jersey:John Wiley \& Sons; 2011.

2. Kusmierek E, Chrzescijanska E. Tannic acid as corrosion inhibitor for metals and alloys. Mater Corros. 2015;66(2):169-74. Doi: https://doi.org/10.1002/maco.201307277

3. Akrout H, Bousselmi L, Triki E, et al. Effect of non-toxic corrosion inhibitors on steel in chloride solution. J Mater Sci. 2004;39:7341-50. Doi: https://doi.org/10.1023/B:JMSC.0000048749.31437.b9

4. Kardas G, Solmaz R. Electrochemical investigation of barbiturates as green corrosion inhibitors for mild steel protection. Corros Rev. 2006;24(3-4):151. Doi: https://doi.org/10.1515/CORRREV.2006.24.3-4.151

5. Solmaz R, Kardas G, Yazıcı B, et al. The Rhodanine inhibition effect on the corrosion of a mild steel in acid along the exposure time. Prot Met. 2007;43:476-82. Doi: https://doi.org/10.1134/S0033173207050104

6. Fathi AM, Mandour HS, Abdel-lkarim AM. The Inhibiting Effect of Non Toxic 4-Amino antipyrine and 4,6- Dimethyl-1H-pyrazolo[3,4-b]pyridin-3amine on Mild steel Corrosion in Sulphuric acid. Int J Electro Chem Sci. 2016;11(7):5580-95. Doi: https://doi.org/10.20964/2016.07.52

7. Prabhu RA, Venkatesha TV, Shanbhag AV, et al. Inhibition effects of some Schiff's bases on the corrosion of mild steel in hydrochloric acid solution. 41Corros Sci. 2008;50(12):3356-62. Doi: https://doi.org/10.1016/j.corsci.2008.09.009

8. Zhang J, Gong XL, Song WW, et al. Synthesis of imidazoline-based dissymmetric bis-quaternary ammonium gemini surfactant and its inhibition mechanism on Q235 steel in hydrochloric acid medium. Mater Corros. 2012;63(7):636-45. Doi: https://doi.org/10.1002/maco.201006051

9. Caliskan N, Akbas E. Corrosion inhibition of austenitic stainless steel by some pyrimidine compounds in hydrochloric acid. Mater Corros. 2012;63(3):231-7. Doi: https://doi.org/10.1002/maco.201005788 
10. Abdel-Gaber AM, Masoud MS, Khalil EA, et al. Electrochemical study on the effect of Schiff base and its cobalt complex on the acid corrosion of steel. Corros Sci. 2009;51(12):3021-24. Doi: https://doi.org/10.1016/j.corsci.2009.08.025

11. Baig RBN, Varma RS. Alternative energy input: mechanochemical, microwave and ultrasound-assisted organic synthesis. Chem Soc Rev. 2012;41:1559-84. Doi: https://doi.org/10.1039/C1CS15204A

12. Finigar M. 2-Mercaptobenzimidazole as a copper corrosion inhibitor: Part II. Surface analysis using X-ray photoelectron spectroscopy. Corros Sci. 2013;72:90-8. Doi: https://doi.org/10.1016/j.corsci.2013.03.010

13. Ongun A, Mert B, Kardas G, et al. Electrochemical and quantum chemical studies of 2-amino-4-methyl-thiazole as corrosion inhibitor for mild steel in $\mathrm{HCl}$ solution. Corros Sci. 2014;83:310-16. Doi: https://doi.org/10.1016/j.corsci.2014.02.029

14. Özcan M, Solmaz R, Kardaş G, et al. Adsorption properties of barbiturates as green corrosion inhibitors on mild steel in phosphoric acid. Colloids Surf. A Physicochem. Eng. Asp. 2008;325(1-2):57-63. Doi: https://doi.org/10.1016/j.colsurfa.2008.04.031

15. Kardas G, Solmaz R. Electrochemical investigation of barbiturates as green corrosion inhibitors for mild steel protection. Corros Rev. 2006;24:151. Doi: https://doi.org/10.1515/CORRREV.2006.24.3-4.151

16. Quraishi MA, Ansari KR, Yadav DK, et al. Corrosion Inhibition and Adsorption Studies of some Barbiturates on Mild Steel/Acid interface. Int J Electrochem Sci. 2012;7(12):12301-15.

17. Udhayakala P, Rajendiran TV, Gunasekaran S. A theoretical study of some barbiturates as corrosion inhibitors for mild steel. J Chem Pharm Res. 2014;6(4):1027-39.

18. Zhang J, Qiao G. Theoretical evaluation of corrosion inhibition performance of imidazoline compounds with different hydrophilic groups. Corros Sci. 2011;53(1):147-52. Doi: https://doi.org/10.1016/j.corsci.2010.09.007

19. Feng L, Yang H. Experimental and theoretical studies for corrosion inhibition of carbon steel by imidazoline derivative in $5 \% \mathrm{NaCl}$ saturated $\mathrm{Ca}(\mathrm{OH}) 2$ solution. Electrochim Acta. 2011;58:427-36. Doi: https://doi.org/10.1016/j.electacta.2011.09.063

20. Rooney DT, Castello NT, Cibulsky M, et al. Materials characterization of the effect of mechanical bending on area array package interconnects. Microelectronics Int. 2003;20(1):34-42. Doi: https://doi.org/10.1108/13565360310455517

21. Finšgar M, Milošev I. Inhibition of copper corrosion by 1,2,3-benzotriazole: A review. Corros Sci. 2010;52(9):2737-49. Doi: https://doi.org/10.1016/j.corsci.2010.05.002

22. Sherif EM. Corrosion Mitigation of Copper in Acidic Chloride Pickling Solutions by 2-Amino-5-ethyl-1,3,4-thiadiazole. J Mater Eng Perform. 2010;19:873-9. Doi: https://doi.org/10.1007/s11665-009-9542-3 
23. $\mathrm{Xu} \mathrm{X,} \mathrm{Zhu} \mathrm{L.} \mathrm{A} \mathrm{variable} \mathrm{hydrophobic} \mathrm{surface} \mathrm{improves} \mathrm{corrosion} \mathrm{resistance}$ of electroplating copper coating. Appl Surf Sci. 2011;257(13):5524-8. Doi: https://doi.org/10.1016/j.apsusc.2011.01.015

24. Wang W, Li Z. Insights into the nature of the coupling interactions between uracil corrosion inhibitors and copper: A DFT and molecular dynamics study. Corros Sci. 2012;61:101-110. Doi: https://doi.org/10.1016/j.corsci.2012.04.025

25. Mazumder MAJ. Synthesis and Evaluation of New Isoxazolidine Derivatives of Aldehyde as Corrosion Inhibitors for Mild Steel Corrosion in Acidic and Saline Media. Int. J Electrochem Sci. 2016;11(5):4050-75. Doi: https://doi.org/10.20964/110257

26. Barcia OE, Mattos OR, Pebere N, et al. Mass-Transport Study for the Electrodissolution of Copper in $1 \mathrm{M}$ Hydrochloric Acid Solution by Impedance. J Electrochem Soc. 1993;140:2825. Doi: https://doi.org/10.1149/1.2220917

27. Duan SZ, Tao YL. Interface Chemistry. Beijing: Higher Education Press; 1990.

28. Ashassi-Sorkhabi H, Ghalebsaz-Jeddi N, Hashemzadeh F, et al. Corrosion inhibition of carbon steel in hydrochloric acid by some polyethylene glycols Electrochim Acta. 2006;51(18):3848-54. Doi: https://doi.org/10.1016/j.electacta.2005.11.002

29. Abdullah AM, Al-Kharafi FM, Ateya BG. Intergranular corrosion of copper in the presence of benzotriazole. Scripta Materialia. 2006;54:1673-7. Doi: https://doi.org/10.1016/j.scriptamat.2006.01.014

30. Udhayakala P, Samuel AM, Rajendiran TV, et al. Theoretical assessment of corrosion inhibition performance of some pyridazine derivatives on mild steel. Chem Pharm Res. 2013;5:142-53.

31. Subramanian R, Lakshminarayanan V. Effect of adsorption of some azoles on copper passivation in alkaline medium. Corros Sci. 2012;44(3):535-54. Doi: https://doi.org/10.1016/S0010-938X(01)00085-3

32. Babic-Samardzija K, Khaled KF, Hackerman N. N-heterocyclic amines and derivatives as corrosion inhibitors for iron in perchloric acid. Anti-Corros Method Mater. 2005;52(1):11-21. Doi: https://doi.org/10.1108/00035590510574871

33. Lokesh KS, De Wael K, Adriaens A. Self-Assembled Supramolecular Array of Polymeric Phthalocyanine on Gold for the Determination of Hydrogen Peroxide. Langmuir. 2010;26(22):17665-73. Doi: https://doi.org/10.1021/la102740s

34. Liang $\mathrm{C}$, Wang $\mathrm{P}, \mathrm{Wu} \mathrm{B}$, et al. Inhibition of copper corrosion by selfassembled monolayers of triazole derivative in chloride-containing solution. J Solid State Electrochem. 2010;14(8):1391-9. Doi: https://doi.org/10.1007/s10008-009-0956-5

35. Juttner K. Electrochemical impedance spectroscopy (EIS) of corrosion processes on inhomogeneous surfaces Electrochim Acta. 1990;35(10):15018. Doi: https://doi.org/10.1016/0013-4686(90)80004-8

36. Rathee P, Tonk RK, Dalal A, et al. Cell Mol Biol. 2016;62:1. 
37. Nechifor G, Pascu D, Pascu M, et al. Comparative study of Temkin and Flory-Huggins isotherms for adsorption of phosphate anion on membranes. UPB Sci Bull. Series B. 2015;77(2):63-72.

38. Goulart CM, Esteves-Souza A, Martinez-Huitle CA, et al. Experimental and theoretical evaluation of semicarbazones and thiosemicarbazones as organic corrosion inhibitors. Corros Sci. 2013;67:281-91. Doi: https://doi.org/10.1016/j.corsci.2012.10.029

39. Amin MA, Ahmed MA, Arida HA, et al. Monitoring corrosion and corrosion control of iron in $\mathrm{HCl}$ by non-ionic surfactants of the TRITON-X series Part II. Temperature effect, activation energies and thermodynamics of $\begin{array}{lll}\text { adsorption. Corros } \quad \text { Sci. } & \text { 2011;53(2):540-8. Doi: }\end{array}$ https://doi.org/10.1016/j.corsci.2010.09.019

40. Martinez S, Stern I. Thermodynamic characterization of metal dissolution and inhibitor adsorption processes in the low carbon steel/mimosa tannin/sulfuric acid system. Appl Surf Sci. 2002;199(1-4):83-9. Doi: https://doi.org/10.1016/S0169-4332(02)00546-9

41. Oguzie EE, Li Y, Wang SG, et al. Understanding corrosion inhibition mechanisms - experimental and theoretical approach. RSC Adv. 2011;1:86673. Doi: https://doi.org/10.1039/C1RA00148E

42. Guan NM, Xueming L, Fei L. Synergistic inhibition between ophenanthroline and chloride ion on cold rolled steel corrosion in phosphoric acid. Mater Chem Phys. 2004;86(1):59-68. Doi: https://doi.org/10.1016/j.matchemphys.2004.01.041

43. Mourya P, Singh P, Tewari AK, et al. Relationship between structure and inhibition behaviour of quinolinium salts for mild steel corrosion: Experimental and theoretical approach. Corros Sci. 2015;95:71-87. Doi: https://doi.org/10.1016/j.corsci.2015.02.034

44. Bockris JO, Reddy AKN. Modern Electrochemistry. Vol 2B, 2nd ed. New York: Kluwer Academic; 2000.

45. Sheriff EM, Erasmus RM, Comins JD. Inhibition of copper corrosion in acidic chloride pickling solutions by 5-(3-aminophenyl)-tetrazole as a corrosion inhibitor. Corros Sci. 2008;50(12):3439-45. Doi: https://doi.org/10.1016/j.corsci.2008.10.002

46. Gao X, Davis JP, Weaver MJ. Test of surface selection rules for surfaceenhanced Raman scattering: the orientation of adsorbed benzene and monosubstituted benzenes on gold. J Phys Chem. 1990;94(17):6858-64. Doi: https://doi.org/10.1021/j100380a059 